J. E. Tulleken

\section{Intensive care medicine curricula in Europe}

Accepted: 10 July 2015

Published online: 28 July 2015

(C) Springer-Verlag Berlin Heidelberg and ESICM 2015

Dear Editor,

I read with interest the article by

Prisco and colleagues on intensive care medicine (ICM) training across the European Union [1]. I agree with the authors that a European common training framework and core curriculum for multidisciplinary ICM is deeply warranted. Unfortunately, Table 1 in the article contains a mistake that we would like to correct because the Netherlands was one of the first adopters of the CoBaTrICE standard. Furthermore we have incorporated EDIC part 1 in our curriculum and part 2 is advised but not mandatory yet.

I am pleased to say that we have implemented the competency-based training model for many years now and would like to share our experiences. Our national ICM program is under the responsibility of the Joint
Intensivists Committee (GIC). We translated the list of ICM competencies and syllabus into Dutch and adapted it to the organization of our ICUs (http://www.cobatrice.org/ Data/ModuleGestionDeContenu/ PagesGenerees/en/10-library/0Alanguages/487.asp). To ensure a high quality level of ICM education and skill acquisition in many domains the GIC harmonizes learning in the nine institutes where fellows are trained across the Netherlands. We organize monthly national educational meetings for ICM fellows and undertake regular educational audits to determine implementation of CoBaTrICE in the institutions and give educators feedback to improve their practice. In 2014 the GIC developed an electronic educational portfolio (EPASS) as a method to support reflection on the process of learning.

CoBaTrICE helps us to continuously improve our ICM education and training program and we hope that a better and more lasting performance of our ICM fellows is the result. Identifying individual quality of skills, attitudes, and practical knowledge still remains a challenge. For the coming years we aim to make steps forward in formalizing aspects of performance and defining degrees of needed supervision by the introduction of the concept of 'entrusted professional activities' (EPAs) as designed by Ten Cate et al. [2]. In short, an EPA combines and translates all competencies that are needed to execute core clinical activities into observable and measurable tasks or responsibilities [2].

Although I am optimistic, I do not know yet whether the EPAs will improve our training program. Clearly, it is important that we all share our successes (and perhaps failures) to add to the further development of an effective and common ICM training framework across the Union.

\section{Compliance with ethical standards}

Conflicts of interest The corresponding author states that there is no conflict of interest. This paper did not receive any grant or funding from any agency in the public, commercial, or not-for-profit sector. An approval by an ethics committee was not applicable.

\section{References}

1. Prisco L, Donadello K, Shepherd SJ (2015) Intensive care medicine curricula in Europe: docendo discimus. Intensive Care Med. doi:

10.1007/s00134-015-3907-x

2. Ten Cate O, Scheele F (2007)

Competency-based postgraduate training: can we bridge the gap between theory and clinical practice. Acad Med 82:542-547

\section{J. E. Tulleken (}

Department of Critical Care, University of Groningen, University Medical Center

Groningen, PO 30.001, 9700 RB,

Groningen, The Netherlands

e-mail: j.e.tulleken@umcg.nl 